\title{
A Case of Severe Asthma where Eosinophilic Granulomatosis with Polyangiitis Became Apparent after the Discontinuation of Dupilumab
}

\author{
Miki Ikeda ${ }^{1}$, Nobuharu Ohshima ${ }^{1}$, Masahiro Kawashima ${ }^{1}$, Meiko Shiina $^{2}$, \\ Masashi Kitani ${ }^{3}$ and Maho Suzukawa ${ }^{1}$
}

\begin{abstract}
:
The use of biologic agents has enabled control of severe asthma, but there is a risk that eosinophilic granulomatosis with polyangiitis (EGPA) may be masked in some cases. We herein report a 71-year-old man who was administered dupilumab for 2 years to stabilize his asthma symptoms. A few months after discontinuation of dupilumab administration, an increase in the eosinophil count in peripheral blood, leg pain, and a rash appeared. Based on pathology, he was diagnosed with EGPA. EGPA in this case was considered to have become apparent due to the discontinuation of dupilumab administration.
\end{abstract}

Key words: severe asthma, dupilumab, eosinophilia, eosinophilic granulomatosis with polyangiitis

(Intern Med Advance Publication)

(DOI: 10.2169/internalmedicine.7990-21)

\section{Background}

Eosinophilic granulomatosis with polyangiitis (EGPA; also known as Churg-Strauss syndrome) is an eosinophilic necrotizing vasculitis that invades small-to-medium-sized blood vessels. EGPA can affect the heart, lungs, kidneys, nerves, and blood vessels (1-3).

The course of EGPA onset has been postulated to be divided into three stages: (i) onset of asthma and eosinophilic sinusitis; (ii) eosinophilia, eosinophilic pneumonia, and asthma exacerbation; (iii) onset of vasculitis. However, the diagnosis of EGPA is very challenging $(1,4,5)$.

Rhinitis and eosinophilic sinusitis are often associated in severe asthma $(6,7)$, which makes it quite complicated to discern whether a case is one of "pure" asthma or preceding disease of EGPA.

The monoclonal antibody dupilumab blocks interleukin (IL)-4 and IL-13 receptors. Dupilumab has been reported to be effective against severe asthma and eosinophilic sinusitis (8). However, in an attempt to control the asthma symptoms by dupilumab, the symptoms of EGPA may also be masked.

We herein report a patient whose asthma was controlled by dupilumab but then developed EGPA five months after the discontinuation of dupilumab treatment.

\section{Case Report}

A 71-year-old Japanese man with no history of smoking developed bronchial asthma while living in the People's Republic of China 13 years earlier. He was an engineer at a manufacturer of electrical goods until retirement. His asthma was treated with pranlukast hydrate $(450 \mathrm{mg} /$ day $)$ and fluticasone propionate/salmeterol xinafoate $(250 / 50 \mu \mathrm{g}$, b.i.d.) via a dry powder (Diskus ${ }^{\mathrm{TM}}$ ) inhaler, but the asthma symptoms persisted. The patient was administered dupilumab (which was an investigational drug at the time) at $600 \mathrm{mg}$ initially, followed by $300 \mathrm{mg}$ every 2 weeks for 94 weeks starting in January 2015. The patient's peripheral blood eosinophil count before the administration of dupilumab was

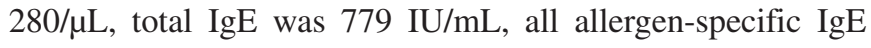
was negative, and $\mathrm{FeNO}$ was $36 \mathrm{ppb}$.

The eosinophil count in peripheral blood increased tran-

${ }^{1}$ Center for Pulmonary Diseases, National Hospital Organization Tokyo National Hospital, Japan, ${ }^{2}$ Department of Neurology, National Hospital Organization Tokyo National Hospital, Japan and ${ }^{3}$ Department of Pathology, National Hospital Organization Tokyo National Hospital, Japan Received: May 18, 2021; Accepted: June 28, 2021; Advance Publication by J-STAGE: August 13, 2021 Correspondence to Dr. Nobuharu Ohshima, oshima-nobuharu@umin.ac.jp 


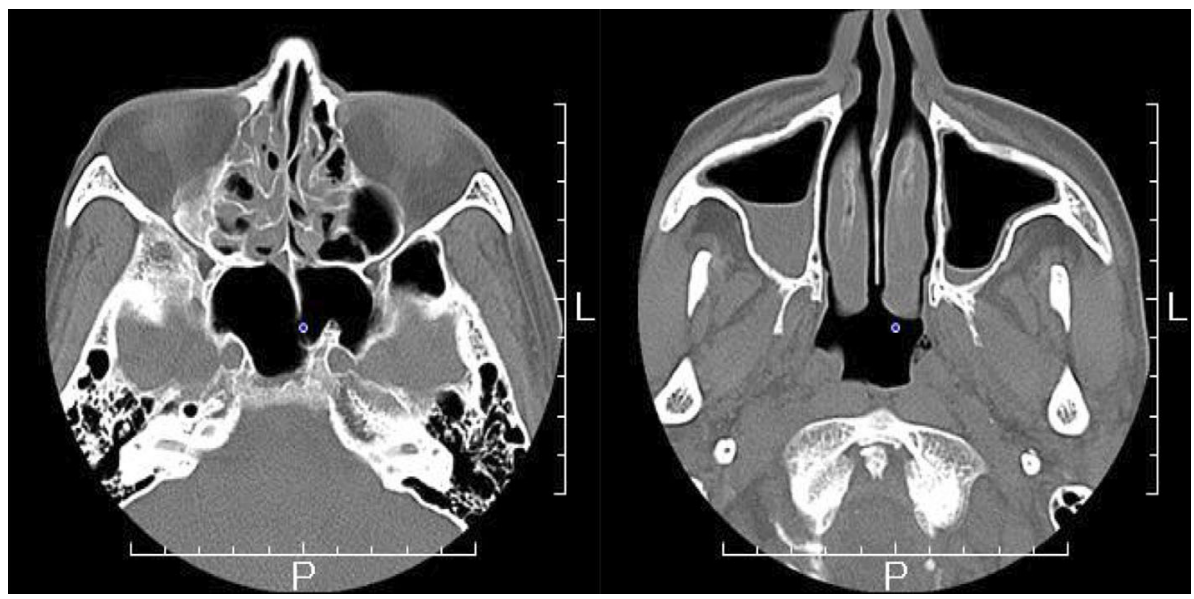

Figure 1. Computed tomography of the sinuses. Mucosal thickening and fluid collection were observed in the right maxillary and bilateral ethmoid sinuses, which were revealed to be signs of sinusitis.

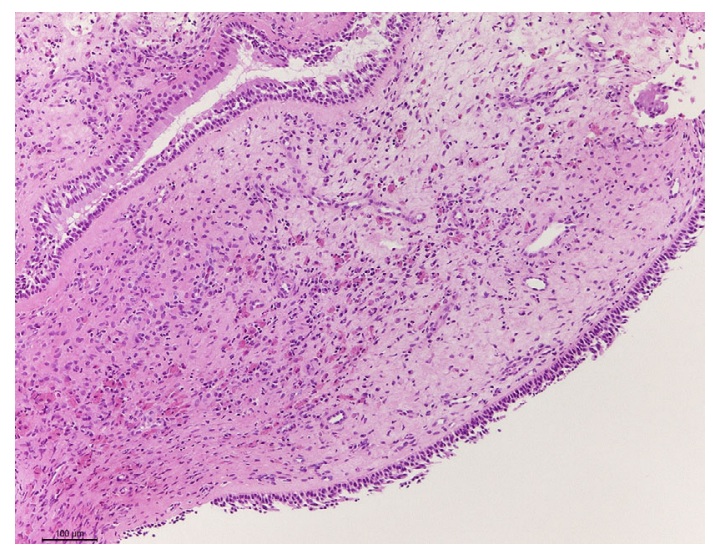

Figure 2. Nasal polyp histology. The specimen showed moderate eosinophil infiltration, which led to the diagnosis of eosinophilic sinusitis. Hematoxylin and Eosin staining, $\times 20$ magnification.

siently to $310 / \mu \mathrm{L}$ at 4 weeks after the start of dupilumab administration but remained in the double-digit range thereafter, and no marked increase in the eosinophil count was observed, with no asthmatic attacks occurring.

However, malaise developed in June 2017 (5 months after completing dupilumab administration), and the eosinophil count in peripheral blood increased to $567 / \mu \mathrm{L}$. Fatigue was exacerbated from mid-August 2017, and a low-grade fever $\left(37^{\circ} \mathrm{C}\right)$ appeared. Rash appeared in both lower limbs in late August 2017. On September 20, 2017, a follow-up examination with his primary physician revealed that the eosinophil count in the peripheral blood had increased to $21,567 / \mu \mathrm{L}$, but no radiological abnormalities were detected in the lungs.

The patient was referred to our hospital on September 27, 2017, where computed tomography of the sinuses revealed sinusitis in the right maxillary sinus and bilateral ethmoid sinuses (Fig. 1). Nasal polyps were identified and biopsied to evaluate (by histology) the abundance of eosinophilic infiltrates. Based on those results, eosinophilic sinusitis was diagnosed (Fig. 2). The patient had been pointed out to have allergic rhinitis in the past but had never been diagnosed with sinusitis previously. In December, bilateral lower-leg pain and plantar hypoesthesia appeared. Mild peripheral neuropathy was suspected because the amplitude in the right sural nerve was $0.6 \mu \mathrm{V}$. The eosinophil count was $12,338 / \mu \mathrm{L}$ at the end of December 2017, pain in both lower legs was exacerbated, and masticatory pain developed. Therefore, the patient was hospitalized in January 2018 for a medical examination and treatment. He had not taken new medicines/ supplements or changed his daily routine after dupilumab administration.

Upon hospital admission, the eosinophil count in peripheral was $8,370 / \mu \mathrm{L}$, and immunoglobulin $(\mathrm{Ig}) \mathrm{E}$ was $541 \mathrm{IU} /$ $\mathrm{mL}$ (Table). The level of anti-neutrophil cytoplasm antibodies was normal. Radiography (Fig. 3) and computed tomography of the chest, and electrocardiography did not show abnormalities. Respiratory function tests showed airway obstruction and fractional exhaled nitric oxide of 29 ppb. We biopsied one of the eruptions on the left thigh, which showed necrotizing vasculitis and necrotizing granulomatosis in the deep dermis extending to the subcutis with eosinophil infiltration (Fig. 4). These pathologic findings were consistent with EGPA according to current diagnostic guidelines (9).

The oral administration of prednisolone at $55 \mathrm{mg} /$ day (1 $\mathrm{mg} / \mathrm{kg}$ body weight/day) was started on January 12, 2018. The eosinophil count at the time of prednisolone administration was $8,370 / \mu \mathrm{L}$. By day 5 of prednisolone administration, the eosinophil count had decreased markedly to $90 / \mu \mathrm{L}$, and pain in the lower legs had improved. Masticatory pain disappeared 1 week after starting oral administration of prednisolone, so the prednisolone dose was reduced to $50 \mathrm{mg} /$ day. Disturbances in the plantar nerve improved gradually after two weeks of prednisolone administration. His symptoms were stable, so the prednisolone dose was reduced by $5 \mathrm{mg}$ every week to $40 \mathrm{mg} / \mathrm{day}$ and then by $5 \mathrm{mg}$ every 2 weeks thereafter. The patient was discharged after the dose had been tapered to $25 \mathrm{mg}$ /day (i.e. day 48 of prednisolone ad- 
Table. Laboratory Data on the Admission.

\begin{tabular}{cclr}
\hline Complete blood count & & CK & $107 \mathrm{U} / \mathrm{L}$ \\
WBC & $13,500 / \mu \mathrm{L}$ & BUN & $15.1 \mathrm{mg} / \mathrm{dL}$ \\
Neutroophil & $27 \%$ & $\mathrm{Cre}$ & $0.7 \mathrm{mg} / \mathrm{dL}$ \\
Lymphocyte & $8 \%$ & $\mathrm{Na}$ & $140 \mathrm{mmol} / \mathrm{L}$ \\
Eosinophil & $62 \%$ & $\mathrm{~K}$ & $4.3 \mathrm{mmol} / \mathrm{L}$ \\
$\mathrm{Hb}$ & $10.8 \mathrm{~g} / \mathrm{dL}$ & $\mathrm{IgG}$ & $1,562 \mathrm{mg} / \mathrm{dL}$ \\
Plt & $29.0 \times 10^{4} / \mu \mathrm{L}$ & $\mathrm{IgA}$ & $201 \mathrm{mg} / \mathrm{dL}$ \\
Laboratory data & & $\mathrm{IgM}$ & $94 \mathrm{mg} / \mathrm{dL}$ \\
TP & $6.3 \mathrm{~g} / \mathrm{dL}$ & $\mathrm{IgE}$ & $541 \mathrm{mg} / \mathrm{dL}$ \\
ALB & $3 \mathrm{~g} / \mathrm{dL}$ & $\mathrm{RF}$ & $164 \mathrm{IU} / \mathrm{mL}$ \\
ALT & $11 \mathrm{U} / \mathrm{L}$ & $\mathrm{MPO}-\mathrm{ANCA}$ & $<1.0 \mathrm{U} / \mathrm{mL}$ \\
AST & $19 \mathrm{U} / \mathrm{L}$ & PR3-ANCA & $<1.0 \mathrm{U} / \mathrm{mL}$ \\
CRP & $1.56 \mathrm{mg} / \mathrm{dL}$ & Aldolase & $19.5 \mathrm{U} / \mathrm{L}$ \\
LDH & $242 \mathrm{U} / \mathrm{L}$ & & \\
\hline
\end{tabular}

ANCA: antineutrophil cytoplasmic antibodies, MPO: myeloperoxidase, PR3: proteinase 3

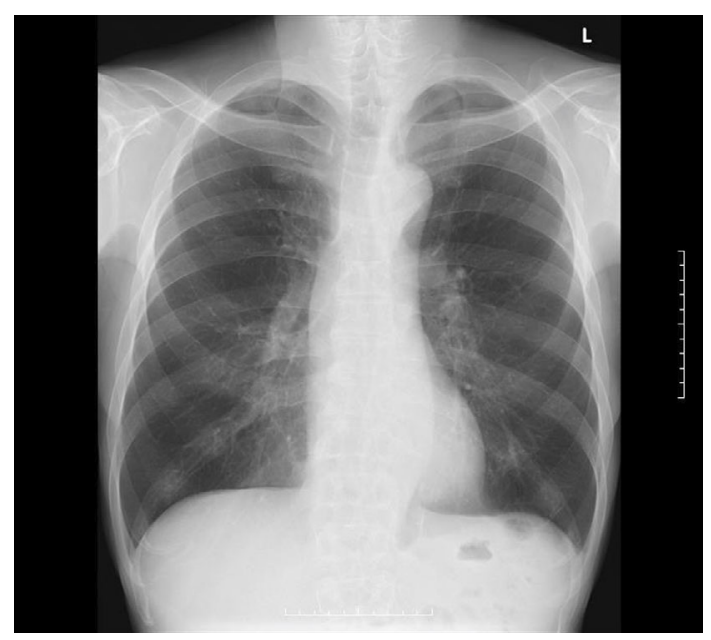

Figure 3. Chest radiography. No obvious abnormality was present in the lung field, and no cardiomegaly or pleural effusion was evident.

ministration). The eosinophil count was maintained at $60 / \mu \mathrm{L}$ and was 0 on the day of hospital discharge. The plantar sensory deficit improved but remained upon hospital discharge.

\section{Discussion}

The incidence of EGPA in Japan is 17.8 per 1 million people, making it a rare disease (10). The response to corticosteroid treatment is good. With appropriate treatment, the survival rate at year 5 is $88 \%-97 \%$, and that at year 10 is $78 \%-89 \%$. (11). However, "fulminant types" of EGPA have been reported to be accompanied by gastrointestinal disorders, cardiac disorders, and cardiac arrest due to fatal ischemia within one to three weeks after the onset of vasculitis $(12,13)$, so it is important to make a diagnosis and perform intervention as soon as possible.

Persistent asthma is a precursor symptom in roughly $90 \%$ of EGPA patients $(14,15)$. It is very difficult to tell if an asthma symptom is a predecessor of EGPA or purely asthma itself, and because EGPA patients often demonstrate severe asthma, systemic corticosteroids and/or biological drugs are sometimes used in addition to inhaled corticosteroids as a treatment for severe asthma.

There have been reports of the relationship between asthma treatments and EGPA diseases, such as leukotriene antagonists (16) and anti-IgE antibody (17). It is presumed that these agents do not cause EGPA directly but instead delay or lead to a decrease in the total dose of systemic corticosteroids due to their anti-asthma effect, thereby making EGPA apparent (2). In a recent report, EGPA was reported to have developed after treatment with monoclonal antibody against IL-5 receptor (benralizumab) (18). In this report, the authors speculated that the improvement of asthma symptoms by benralizumab led to the reduction of systemic corticosteroids as an asthma-controlling agent and resulted in the development of EGPA.

There are three possibilities as to why EGPA developed in our patient. First, after the discontinuation of dupilumab administration, the patient may have experienced the natural course of the EGPA onset. The onset of bronchial asthma started 13 years previously for our patient, and asthma was complicated by eosinophilic sinusitis, which is in accordance with the clinical process of EGPA. Second, dupilumab might have suppressed the manifestations of EGPA, but EGPA may have become apparent after dupilumab discontinuation. Granulocyte macrophage-colony stimulating factor (GM-CSF) is involved in eosinophil activation (19), and IL4 and IL-13 promote GM-CSF production from human bronchial epithelial cells (20). Culturing eosinophils in the presence of periostin or eotaxin has been reported to lead to production of reactive oxygen species and degranulation of eosinophil-derived neurotoxin from eosinophils $(21,22)$. IL4 and IL-13 regulate the expression of periostin and eotaxin $(23,24)$. Hence, IL-4 and IL-13 are involved in eosinophil activation through GM-CSF, periostin, and eotaxin. Dupilmab blocks IL-4 and IL-13 receptors and suppresses eosinophil activation. We cannot exclude the hy- 


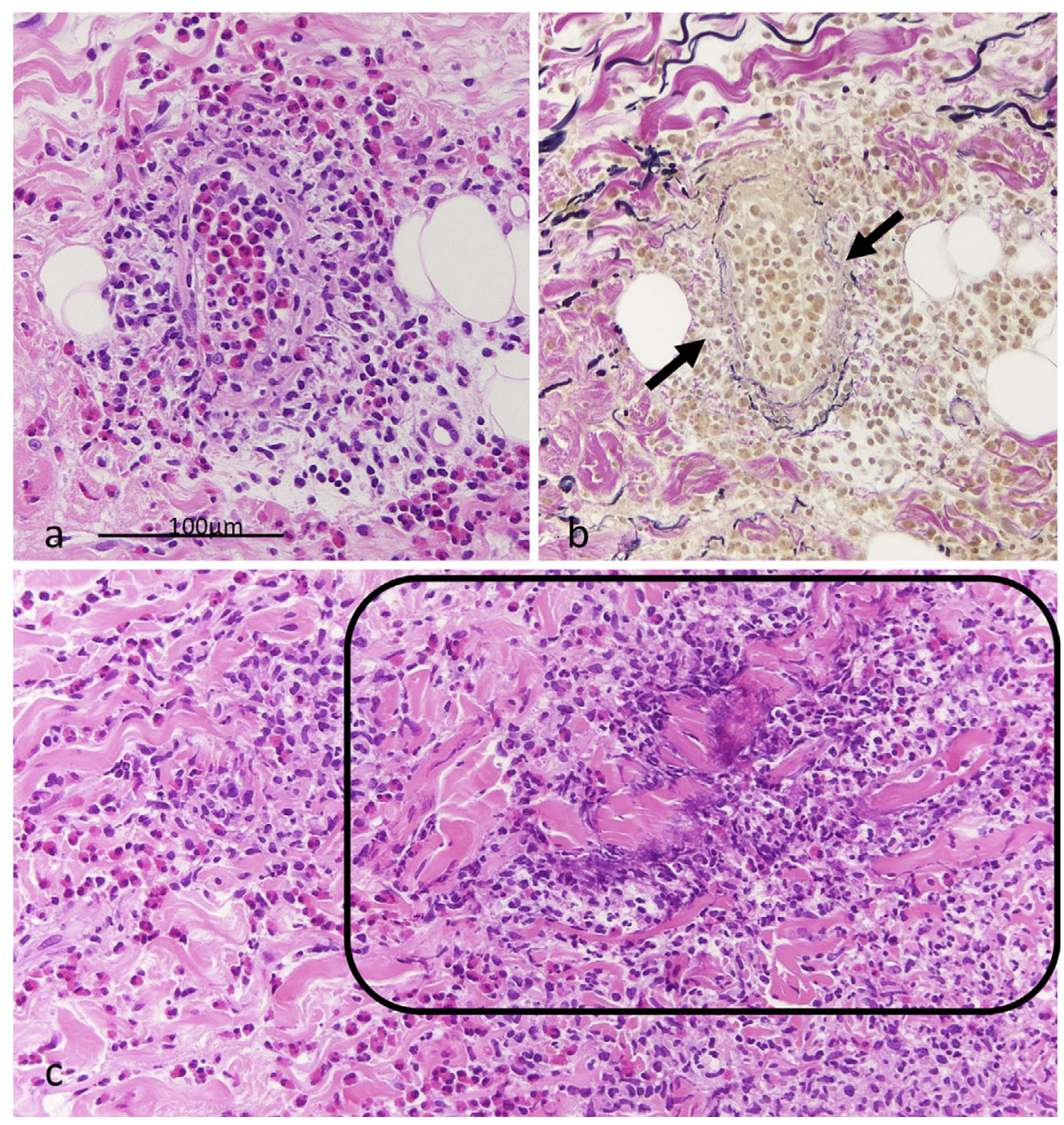

Figure 4. Histology of skin eruptions. (a) Eosinophil-rich inflammation and necrotizing vasculitis. Hematoxylin and Eosin (H\&E) staining, $\times 20$ magnification. (b) Nearly the same area as shown in (a). Elastic fibers in the blood vessels have been disrupted, showing necrotizing vasculitis (arrows). Elastin van Gieson, $\times 20$ magnification. (c) Necrotizing granulomatosis with marked eosinophilia. H\&E staining, $\times 20$ magnification.

pothesis that dupilumab administration may have masked the potential for EGPA. Third, dupilumab may have caused EGPA. Eosinophilia during treatment has been reported as an adverse event of dupilumab, with a prevalence of $4.1 \%$ $14 \%(25,26)$. Castro et al. observed that an increased eosinophil count in blood was associated with symptoms in four patients who received dupilumab, and two of these events were reported as serious adverse events (worsening of hypereosinophilia and chronic eosinophilic pneumonia) (26). Menzella et al. also reported chronic eosinophilic pneumonia following dupilumab treatment (27).

Bachert et al. reported the development of EGPA during and after dupilumab administration (8), but the mechanism has not been elucidated. In addition, a case wherein clinical symptoms similar to EGPA developed after switching from anti-IL-5 or anti-IL-5R antibodies to dupilumab was reported recently (28).

In the present case, dupilumab administration may have triggered the onset of EGPA. The number of biologic agents used for asthma treatment is expected to increase. If there is an increase in the eosinophil count while tapering systemic corticosteroids as asthma-controlling agents as a result of the administration of biologic agents or after administration of biologic agents, then careful observation, while keeping in mind the risk of EGPA, is important. We hope that this case report will serve as a reference for many physicians involved in the treatment of severe asthma.

Author's disclosure of potential Conflicts of Interest (COI). Nobuharu Ohshima: Honoraria, GlaxoSmithKline. and AstraZeneca K.K.

\section{Acknowledgement}

We would like to express our deep gratitude to Dr. Hisaho Takahashi (Takahashi Clinic) for providing us with the valuable patient data for this case.

\section{References}

1. Vaglio A, Buzio C, Zwerina J. Eosinophilic granulomatosis with polyangiitis (Churg-Strauss): state of the art. Allergy 68: 261-273, 2013.

2. Gioffredi A, Maritati F, Oliva E, Buzio C. Eosinophilic granulo- 
matosis with polyangiitis: an overview. Front Immunol 5: 549, 2014.

3. Noth I, Strek ME, Leff AR. Churg-Strauss syndrome. Lancet 361: 587-594, 2003.

4. Pagnoux C, Guillevin L. Churg-Strauss syndrome: evidence for disease subtypes? Curr Opin Rheumatol 22: 21-28, 2010.

5. Lanham JG, Elkon KB, Pusey CD, Hughes GR. Systemic vasculitis with asthma and eosinophilia: a clinical approach to the ChurgStrauss syndrome. Medicine 63: 65-81, 1984.

6. Gandhi NA, Bennett BL, Graham NM, Pirozzi G, Stahl N, Yancopoulos GD. Targeting key proximal drivers of type 2 inflammation in disease. Nat Rev Drug Discov 15: 35-50, 2016.

7. Bousquet J, Khaltaev N, Cruz AA, et al. Allergic rhinitis and its impact on asthma (ARIA) 2008 update (in collaboration with the World Health Organization, GA(2)LEN and AllerGen). Allergy 63: 8-160, 2008.

8. Bachert C, Han JK, Desrosiers M, et al. Efficacy and safety of dupilumab in patients with severe chronic rhinosinusitis with nasal polyps (LIBERTY NP SINUS-24 and LIBERTY NP SINUS-52): results from two multicentre, randomised, double-blind, placebocontrolled, parallel-group phase 3 trials. Lancet 394: 1638-1650, 2019.

9. Masi AT, Hunder GG, Lie JT, et al. The American College of Rheumatology 1990 criteria for the classification of Churg-Strauss syndrome (allergic granulomatosis and angiitis). Arthritis Rheum 33: 1094-1100, 1990.

10. Sada KE, Amano K, Uehara R, et al. A nationwide survey on the epidemiology and clinical features of eosinophilic granulomatosis with polyangiitis (Churg-Strauss) in Japan. Mod Rheumatol 24: 640-644, 2014

11. Furuta $S$, Iwamoto $T$, Nakajima $H$. Update on eosinophilic granulomatosis with polyangiitis. Allergol Int 68: 430-436, 2019.

12. Hervier B, Masseau A, Bossard C, Agard C, Hamidou M. Vasavasoritis of the aorta and fatal myocarditis in fulminant ChurgStrauss syndrome. Rheumatology 47: 1728-1729, 2008.

13. Setoguchi M, Okishige K, Sugiyama K, et al. Sudden cardiac death associated with Churg-Strauss syndrome. Circ J 73: 2355$2359,2009$.

14. Comarmond C, Pagnoux C, Khellaf M, et al. Eosinophilic granulomatosis with polyangiitis (Churg-Strauss): clinical characteristics and long-term followup of the 383 patients enrolled in the French Vasculitis Study Group cohort. Arthritis Rheum 65: 270-281, 2013.

15. Cottin V, Bel E, Bottero P, et al. Revisiting the systemic vasculitis in eosinophilic granulomatosis with polyangiitis (Churg-Strauss): a study of 157 patients by the Groupe d'Etudes et de Recherche sur les Maladies Orphelines Pulmonaires and the European Respiratory Society Taskforce on eosinophilic granulomatosis with polyangiitis (Churg-Strauss). Autoimmun Rev 16: 1-9, 2017.

16. Wechsler ME, Garpestad E, Flier SR, et al. Pulmonary infiltrates, eosinophilia, and cardiomyopathy following corticosteroid with- drawal in patients with asthma receiving zafirlukast. JAMA 279: 455-457, 1998.

17. Wechsler ME, Wong DA, Miller MK, Lawrence-Miyasaki L. Churg-Strauss syndrome in patients treated with omalizumab. Chest 136: 507-518, 2009.

18. Hočevar A, Kopač P, Rotar Ž, Novljan MP, Škrgat S. Eosinophilic granulomatosis with polyangiitis evolution during severe eosinophilic asthma treatment with benralizumab. J Allergy Clin Immunol Pract 8: 2448-2449, 2020.

19. Liu LY, Sedgwick JB, Bates ME, et al. Decreased expression of membrane IL-5 receptor alpha on human eosinophils: I. Loss of membrane IL-5 receptor alpha on airway eosinophils and increased soluble IL-5 receptor alpha in the airway after allergen challenge. J Immunol 169: 6452-6458, 2002.

20. Nakamura Y, Azuma M, Okano Y, et al. Upregulatory effects of interleukin-4 and interleukin-13 but not interleukin-10 on granulocyte/macrophage colony-stimulating factor production by human bronchial epithelial cells. Am J Respir Cell Mol Biol 15: 680-687, 1996.

21. Noguchi T, Nakagome K, Kobayashi T, et al. Periostin upregulates the effector functions of eosinophils. J Allergy Clin Immunol 138: 1449-1452.e5, 2016.

22. Fujisawa $T$, Kato $Y$, Nagase $H$, et al. Chemokines induce eosinophil degranulation through CCR-3. J Allergy Clin Immunol 106: 507-513, 2000.

23. Sidhu SS, Yuan S, Innes AL, et al. Roles of epithelial cell-derived periostin in TGF-beta activation, collagen production, and collagen gel elasticity in asthma. Proc Natl Acad Sci U S A 107: 1417014175, 2010.

24. Stellato C, Matsukura S, Fal A, et al. Differential regulation of epithelial-derived C-C chemokine expression by IL-4 and the glucocorticoid budesonide. J Immunol 163: 5624-5632, 1999.

25. Rabe KF, Nair P, Brusselle G, et al. Efficacy and safety of dupilumab in glucocorticoid-dependent severe asthma. N Engl J Med 378: 2475-2485, 2018.

26. Castro M, Corren J, Pavord ID, et al. Dupilumab efficacy and safety in moderate-to-severe uncontrolled asthma. N Engl J Med 378: 2486-2496, 2018.

27. Menzella F, Montanari G, Patricelli G, et al. A case of chronic eosinophilic pneumonia in a patient treated with dupilumab. Ther Clin Risk Manag 15: 869-875, 2019.

28. Eger K, Pet L, Weersink EJM, Bel EH. Complications of switching from anti-IL-5 or anti-IL-5R to dupilumab in corticosteroiddependent severe asthma. J Allergy Clin Immunol Pract S22132198(21)00247-6, 2021.

The Internal Medicine is an Open Access journal distributed under the Creative Commons Attribution-NonCommercial-NoDerivatives 4.0 International License. To view the details of this license, please visit (https://creativecommons.org/licenses/ by-nc-nd/4.0/).

\section{(C) The Japanese Society of Internal Medicine Intern Med Advance Publication}

